\title{
Isoprostane in systemic sclerosis: a systematic review and meta-analysis
}

\section{Paul RJ Ames, Mira Merashli, Tommaso Bucci \& Jaffar Norouz-Zadeh}

To cite this article: Paul RJ Ames, Mira Merashli, Tommaso Bucci \& Jaffar Norouz-Zadeh (2018): Isoprostane in systemic sclerosis: a systematic review and meta-analysis, Modern Rheumatology, DOI: $10.1080 / 14397595.2018 .1469458$

To link to this article: https://doi.org/10.1080/14397595.2018.1469458

Accepted author version posted online: 25 Apr 2018.

Submit your article to this journal $\widetilde{T}$

Q View related articles $₫$

View Crossmark data $₫$ 


\section{MORH-D-18-00040 Received: 25-Jan-2018; Accepted: 23-Apr-2018}

\section{$\underline{\text { Original Article }}$}

Isoprostane in systemic sclerosis: a systematic review and meta-analysis

Paul RJ Ames ${ }^{1}$, Mira Merashli ${ }^{2}$, Tommaso Bucci ${ }^{3}$, Jaffar Norouz-Zadeh $^{4}$

${ }^{1}$ Immune Response and Vascular Disease Unit, CEDOC, Nova University Lisbon, Rua Camara Pestana, Lisbon Portugal; Department of Haematology, Dumfries Royal Infirmary, Cargenbridge, Dumfries, UK; ${ }^{2}$ Department of Rheumatology, American University of Beirut, Bliss, Beirut, Lebanon; ${ }^{3}$ Division of Allergy and Clinical Immunology, University of Salerno, Via San Leonardo, 1, Salerno, Italy; ${ }^{4}$ Department of Clinical Biochemistry, Urmia University of Medical Sciences, West Azerbaijan Province 24, Urmia, Iran.

Number of text pages: 10, Number of tables: 2, Number of figures: 4

Corresponding author: Paul RJ Ames,

Department of Haematology, Dumfries Royal, Infirmary, Dumfries, UK.

E-mail: paxmes@aol.com; Phone: 00441387 246246; Fax: 00441387216246 


\section{Abstract}

Objectives: to further the knowledge of oxidative stress in systemic sclerosis ( $\mathrm{SSc}$ ) we performed a systematic review and meta-analysis on studies measuring isoprostane, a vasoactive agent deriving from arachidonic acid and implicated in the vasculopathy of SSc. Methods: systematic search following the PRISMA guidelines in PubMed and EMBASE between January-1990/December-2017 using the terms: oxidative stress, isoprostane, systemic sclerosis, scleroderma.

Results: After the screening process 8 studies including 240 SSc patients and 192 controls were included in the systematic review and meta-analysis, 6 investigating urinary and 2 serum isoprostane: random effect metaanalysis revealed isoprostane overgeneration in $\operatorname{SSc}(\mathrm{p}<0.001)$ with wide heterogeneity $\left(\mathrm{I}^{2}=75 \%\right)$. Subgroup analysis on urinary isoprostane favoured excess excretion in $\mathrm{SSc}(\mathrm{p}=0.009)$ with slightly lower heterogeneity $\left(\mathrm{I}^{2}=67 \%\right)$; further subgroup analysis according to unit of measurement revealed no increased isoprostane excretion when expressed as $\mathrm{pg} / \mathrm{mg}$ creatinine but increased when expressed as $\mathrm{pmol} / \mathrm{mmol}$ creatinine $(\mathrm{p}=0.05)$ with medium heterogeneity $\left(\mathrm{I}^{2}=32 \%\right)$. Subgroup analysis on serum isoprostane favoured overproduction in SSc $(\mathrm{p}<0.0001)$ with no heterogeneity. Conclusions: there is some evidence for isoprostane overgeneration in SSc that confirms the occurrence of oxidative stress in this setting: further prospective studies with specified outcomes are needed to evaluate the prognostic value of this functional biomarker.

Key words: isoprostane, oxidative stress, systemic sclerosis

\section{Introduction}

An excess of free radical generation that overrides a normal or a decreased cellular or plasma antioxidant capacity favours oxidative stress: in given microenvironments free radical attack on arachidonic acid may give raise to cyclic compounds termed isoprostanes (IPTs) in the absence of cyclooxygenase activity (1). IPTs are powerful vasoactive agents (1) that circulate in plasma, are filtered through the kidney and are excreted in the urine (2,3): in humans two major urinary metabolites of 15-IPT have been identified: 2,3-dinor-15 and 2,3dinor- 5,6-dihydro-15 IPT $(4,5,6$,$) ; the liver metabolises IPT into several other derivatives (4-9) such as 13,14-$ dihydro-15-keto- and 2,3,4,5-tetranor- IPT alongside several taurine and glucuronide conjugates $(8,9)$. IPT is widely used as a biomarker of total body oxidative stress (6) and elevated serum or urinary levels have been detected in a variety of autoimmune rheumatic diseases including: 1) systemic lupus erythematosus $(10,11)$ 
where IPT showed a relationship with disease activity (11) and a U-shaped relationship with the daily steroid dose taken by patients $(10) ; 2)$ antiphospholipid syndrome, where serum and urinary IPT levels were reduced by different short term antioxidant treatments $(12,13) ; 3)$ in systemic vasculitis (10) including Behcet's disease (14); 4) in rheumatoid arthritis (15) where IPT was quenched by anti tumour necrosis factor blockers (16).

Oxidative stress is deeply implicated in the vascular pathogenesis of systemic sclerosis (SSc) and the imbalance between excess oxidation in the face of reduced antioxidant defence was recently appraised in this setting (17). According to this meta-analysis, the oxidant compounds nitric oxide, malondialdehyde, homocysteine and carbonyl were significantly increased in SSc whereas the antioxidant compounds vitamin E and thiols were decreased alongside a reduced antioxidant activity of catalase and of the total antioxidant capacity of plasma; however the authors did not include IPT amongst their oxidative stress markers (17). IPT relates negatively to post-occlusion hyperemia (18) and pulmonary function (percentage vital capacity and diffusion capacity for carbon monoxide) (19) whereas it positively correlates to nail fold morphological capillaroscopic pattern (20), severity of lung involvement (20) and renal vascular damage (19). To fill the gap left by the previous meta-analysis and to gain more information on the significance of IPT in SSc we performed a systematic review and meta-analysis on this specific molecule and the results are presented herein.

\section{Methods}

The PubMed and EMBASE databases were searched according to the PRISMA guidelines (21) from 1990, year of IPT discovery (22), to December 2017, using the following terms: oxidative stress, IPT, systemic sclerosis, scleroderma. Articles were included if they addressed the difference in mean urinary or serum concentration of IPT between SSc patients and healthy controls; they were excluded if not written in English. Two investigators (MM and PRJA) screened all abstracts and papers to identify studies appropriate for inclusion according to date of publication, language, study design, participant data and results. We assessed the quality of the selected studies by the Newcastle Ottawa Quality Assessment Scale (NOW) (23). The primary outcome was the mean differences of urinary or serum IPT between SSc and healthy control groups and a likely secondary outcome was the mean difference between diffuse and limited SSc. The statistical analysis was carried out using Comprehensive Meta-Analysis, BioStat, Englewood, NJ, USA. We employed random effects meta-analyses for continuous outcomes as the IPT estimates were the result of observational studies rather than planned experiments (24). Statistical heterogeneity was estimated by $\mathrm{I}^{2}$ statistics: an $\mathrm{I}^{2}$ value of $0 \%$ indicated no heterogeneity; values less than $25 \%$ indicate low, between $25-50 \%$ moderate and over $50 \%$ high heterogeneity. 
Subgroup analyses were based on clinical judgment, on biological fluids from which IPT was measured and on the unit of measurements by which IPT was expressed. We did not rely on funnel plots for their known inadequacy particularly when the number of studies included in the meta-analysis is small as in ours and because funnel plots can give a wrong impression of publication bias when high precision studies are much different in terms of effect size from low precision studies $(25,26)$.

\section{Results}

\section{Data expression and quality of individual studies}

At the end the screening process (Figure 1), 8 studies were included in the analysis: 6 investigated urinary IPT $(18,20,27-30)$ and 2 serum IPT $(10,19)$. One study (18) expressed results in median and percentile ranges $\left(10^{\text {th }}, 90^{\text {th }}\right)$ (Tables $\left.1 \mathrm{~A} \& \mathrm{~B}\right)$; the percentile data were arbitrarily transformed into standard deviation (SD) assuming the $10^{\text {th }}$ percentile is 1.28 times the SD below the mean and the $90^{\text {th }}$ percentile is 1.28 times the SD above the mean and the two resulting values were averaged to yield a SD. A second study (20) expressed results in mean and $95 \%$ confidence intervals (CI) and were transformed into mean $\pm \mathrm{SD}$ according to the formula: $\mathrm{S} 2=\mathrm{n} 2 *[\mathrm{X}-\mathrm{CI}(1)] / 1.96$ where $\mathrm{X}=$ mean of $95 \% \mathrm{CI}$ and $\mathrm{n}=$ sample number. A third study (30) expressed results in median and interquartile ranges (IQR) (15): the IQR was divided by 1.35 (approximately the equivalence in SD of the IQR) assuming a normal distribution (Table 1B). Three studies expressed the results in mean and standard error of mean (SEM) (27-29): the latter was converted to standard deviation (SD) according to the formula SD = SEM $\mathrm{x} \sqrt{ } \mathrm{n}$, where $\mathrm{n}$ is the sample size. A further study (19) expressed results in median and range that were transformed into estimated mean and SD (31). All studies ranked relatively well on the NOW (Table 1A); the inter-rater agreement of the 2 investigators (MA and PRJA) was 0.55 (95\% CI 0.157, 0.954) (Cohen's weighted kappa).

\section{Effect size results}

Data from the 8 studies comprising 240 SSc patients and 192 controls were pooled for the effect size of this outcome. Random effect meta-analysis revealed wide heterogeneity $\left(I^{2}=75 \%, p<0.0001\right)$ amongst the 8 studies (Figure 2): subgroup analysis carried out on studies measuring urinary IPT favoured excess urinary excretion in SSc ( $\mathrm{p}=0.002)$ with slightly lower heterogeneity $\left(\mathrm{I}^{2}=67 \%\right)$ (Figure $\left.3 \mathrm{~A}\right)$; further sub-grouping according to unit of measure did not reveal over-excretion of urinary IPT in studies expressing it as $\mathrm{pg} / \mathrm{mg}$ creatinine (Figure 3B) that was present instead in those studies expressing it as $\mathrm{pmol} / \mathrm{mmol}$ creatinine $(\mathrm{p}=0.05)$ with medium 
heterogeneity $\left(\mathrm{I}^{2}=32 \%\right)$ (figure $\left.3 \mathrm{C}\right)$. The heterogeneity was still high after sub-grouping the analysis by method of IPT measurement: gas chromatoghraphy-mass spectrometry $(10,18,27-29)$, high pressure liquid chromatography (20) and enzyme immunoassay $(19,30)\left(\mathrm{I}^{2}=84.3 \%, \mathrm{p}<0.0001\right.$, graph not shown). On the other hand, pooled data on serum IPT favoured overproduction in SSc $(\mathrm{p}<0.0001)$ with no heterogeneity (Figure 3D).

Pooled data from five studies $(27,28,30)$ allowed a comparison between 77 patients with diffuse and 63 with limited disease: three studies investigated urinary and two serum IPT; random effect meta-analysis revealed overproduction of IPT in limited disease $(\mathrm{p}=0.01)\left(\mathrm{I}^{2}=0 \%\right)$ (graph not shown) accounted all by the serum data from Ogawa et al. (19). In the diffuse disease group of this study two outliers markedly influenced the overall results and therefore this study (19) was omitted from the meta-analysis that was carried only on the studies on urinary isoprostane the excretion of which was not different between diffuse and limited disease (Figure 4).

\section{Discussion}

This meta-analysis confirms the occurrence of oxidative stress in SSc (17) measured by a functional biomarker: in fact IPT is not only a potent vasoconstrictor (32) but it is able to stimulate endothelin-1 release by endothelial cells (33): both agents are deeply implicated in the vasculopathy of $\operatorname{SSc}(18-20,34)$. However the significant effect size seen for all the studies pooled together was offset by wide heterogeneity, particularly with regards to urinary IPT: the heterogeneity did not decrease after splitting the studies on urinary IPT by unit of measurement, but when the two studies on serum IPT were pooled together there was evidence for IPT overproduction devoid of heterogeneity $(10,19)$.

Having excluded methodological issues with IPT measurement, large part of the heterogeneity must be intrinsic to the patient populations under study: urinary IPT excretion did not differ between limited and disease diffuse despite the latter being an independent predictor of death in SSc (35). Studies varied with regards to disease activities and organ involvement, and though the prevalence of pulmonary fibrosis was not too dissimilar, not all authors reported in their studies the frequency of pulmonary arterial hypertension and renal involvement, clinical manifestations related to IPT overproduction $(19,20)$ and leading causes of death in SSc (35). Additional factors as dietary intake (36), social habits such as alcohol intake and smoking are known to affect oxidative stress and may confound the above relationships $(37,38)$. We did not engage in the effects of publication bias because this can be influenced by the limited number of studies included in the meta-analysis $(24,25)$. 
As more knowledge on the mechanism of free radical damage in SSc accrues (39), a post-treatment decrease in IPT may be useful to define whether certain drugs or supplements employed for the management of SSc may have antioxidant properties (30). However, given the limited and heterogeneous data available, further prospective studies are needed to understand whether IPT may bear prognostic relevance with regards to morbidity and mortality in SSc before being considered as a clinically relevant biomarker in SSc.

\section{Acknowledgments}

We are grateful to www.FondazioneAps.org, and Italian Registered Charity for its support

\section{Conflict of interest}

None

\section{References}

1) Nourooz-Zadeh J. Key issues in F2-isoprostane analysis. Biochem Soc Trans 2008; 36:1060-1065

2) Praticò D, Barry OP, Lawson JA, Adiyaman M, Hwang SW, Khanapure SP et al. iPF2alpha-I: an index of lipid peroxidation in humans. Proc Natl Acad Sci USA 1998; 95: 3449-3454

3) Li H, Lawson JA, Reilly M, Adiyaman M, Hwang SW, Rokach J et al. Quantitative high performance liquid chromatography/tandem mass spectrometric analysis of the four classes of $\mathrm{F}_{2}$-isoprostanes in human urine. Proc Natl Acad Sci U S A. 1999; 96: 13381-13386.

4) Roberts LJ, II, Moore KP, Zackert WE, Oates JA, Morrow JD. Identification of the major urinary metabolite of the $\mathrm{F}_{2}$-isoprostane 8-iso-prostaglandin F2alpha in humans. J Biol Chem 1996; 271: 20617 20620 .

5) Schwedhelm E, Tsikas D, Durand T, Gutzki FM, Guy A, Rossi JC et al. Tandem mass spectrometric quantification of 8-iso-prostaglandin F2alpha and its metabolite 2,3-dinor-5,6-dihydro-8-iso-prostaglandin F2alpha in human urine. J Chromatogr B Biomed Sci Appl 2000; 744: 99-112

6) Nourooz-Zadeh J, Cooper MB, Ziegler D, Betteridge DJ. Urinary 8-epi-PGF2alpha and its endogenous beta-oxidation products (2,3-dinor and 2,3-dinor-5,6-dihydro) as biomarkers of total body oxidative stress. Biochem Biophys Res Commun 2005; 330:731-736 
7) Awad JA, Morrow JD, Takahashi K, Roberts LJ II. Identification of non-cyclooxygenase-derived prostanoid ( $\mathrm{F}_{2}$-isoprostane) metabolites in human urine and plasma. J Biol Chem 1993; 268: 4161-4169.

8) Chiabrando C, Rivalta C, Bagnati R, Valagussa A, Durand T, Guy A et al. Identification of metabolites from type III $\mathrm{F}_{2}$-isoprostane diaste-reoisomers by mass spectrometry. J Lipid Res. 2002; 43:495-509.

9) Yan Z, Mas E, Mori TA, Croft KD, Barden AE. A significant proportion of $\mathrm{F}_{2}$-isoprostanes in human urine are excreted as glucuronide conjugates. Anal Biochem. 2010; 403:126-128

10) Ames PRJ, Alves J, Murat I, Isenberg DA, Nourooz-Zadeh J. Oxidative stress in systemic lupus erythematosus and allied conditions with vascular involvement. Rheumatology 1999; 38: 529-534

11) Avalos I, Chung CP, Oeser A, Milne GL, Morrow JD, Gebretsadik T et al. Oxidative stress in systemic lupus erythematosus: relationship to disease activity and symptoms. Lupus 2007;16: 195-200

12) Ames PR, Tommasino C, Alves J, Morrow JD, Iannaccone L, Fossati G et al. Antioxidant susceptibility of pathogenic pathways in subjects with antiphospholipid antibodies: a pilot study. Lupus. 2000; 9: 688-695

13) Ferro D, Saliola M, Meroni PL, Valesini G, Caroselli C, Praticò D et al. Enhanced monocyte expression of tissue factor by oxidative stress in patients with antiphospholipid antibodies: effect of antioxidant treatment. J Thromb Haemost 2003; 1: 523-531

14) Sagun G, Oguz A, Mesci B, Isbilen B, Kavala M, Keskin H et al. Levels of F2 isoprostane in Behcet's disease: Correlation with cardiometabolic risk factors.Redox Rep 2015; 20: 223-227

15) Łuczaj W, Gindzienska-Sieskiewicz E, Jarocka-Karpowicz I, Andrisic L, Sierakowski S, Zarkovic N et al. The onset of lipid peroxidation in rheumatoid arthritis: consequences and monitoring. Free Radic Res 2016; 50: $304-313$

16) Kageyama Y, Takahashi M, Ichikawa T, Torikai E, Nagano A. Reduction of oxidative stress marker levels by anti-TNF-alpha antibody, infliximab, in patients with rheumatoid arthritis. Clin Exp Rheumatol 2008; 26: $73-80$

17) Luo JY, Liu X, Jiang M, Zhao HP, Zhao JJ. Oxidative stress markers in blood in systemic sclerosis: A meta-analysis. Mod Rheumatol 2017; 27: 306-314

18) Cracowski JL, Kom GD, Salvat-Melis M, Renversez JC, McCord G, Boignard A et al. Postocclusive reactive hyperemia inversely correlates with urinary 15-F2t-isoprostane levels in systemic sclerosis. Free Radical Biol Med 2006; 40: 1732-1737

19) Ogawa F, Shimizu K, Muroi E, Hara T, Hasegawa M, Takehara K, et al. Serum levels of 8-isoprostane, a marker of oxidative stress, are elevated in patients with systemic sclerosis. Rheumatol 2006; 45: 815-818 
20) Volpe A, Biasi D, Caramaschi P, Mantovani W, Bambara LM, Canestrini S et al. Levels of F2-isoprostanes in systemic sclerosis: correlation with clinical features. Rheumatol 2006; 45: 314-320

21) Liberati A, Altman DG, Tetzlaff J, Mulrow C, Gotzsche PC, Ioannidis JP et al. The PRISMA statement for reporting systematic reviews and meta-analyses of studies that evaluate health care interventions: explanation and elaboration. Ann Intern Med 2009; 1514: 65-94

22) Morrow JD, Hill KE, Burk RF, Nammour TM, Badr KF, Roberts LJ 2nd. A series of prostaglandin F2-like compounds are produced in vivo in humans by a non-cyclooxygenase, free radical-catalyzed mechanism. PNAS 1990; 87: 9383-9387

23) Wells GA, Shea B, O’Connell D, Peterson J, Welch V, Losos M et al. Ottawa Hospital Research Institute. The Newcastle-Ottawa Scale (NOS) for assessing the quality of non randomized studies in meta-analyses. URL: www.ohri.ca/programs/clinical_epidemiology / oxford.htm

24) Riley RD, Higgins JPT, Deeks JJ. Interpretation of random effects meta-analyses. Br Med J 2001; 342: d549

25) Lau J, Ioannidis JPA, Terrin N, Schmid CH, Olkin I. The case of the misleading funnel plot. Br Med J 2006; 333: 597-600

26) Tang JL, Liu JL. Misleading funnel plot for detection of bias in meta-analysis. Clin Epidemiol 2000; 253: $477-484$

27) Stein CM, Tanner SB, Awad JA, Roberts LJ, 2nd, Morrow JD. Evidence of free radicalmediated injury (isoprostane overproduction) in scleroderma. Arthritis Rheum 1996; 39: 1146-1150

28) Cracowski JL, Marpeau C, Carpentier PH, Imbert B, Hunt M, Stanke-Labesque F et al. Enhanced in vivo lipid peroxidation in scleroderma spectrum disorders. Arthritis Rheum 2001; 44: 1143-1148

29) Cracowski JL, Carpentier PH, Imbert B, Cachot S, Stanke-Labesque F, Bessard J et al. Increased urinary F2-isoprostanes in systemic sclerosis, but not in primary Raynaud's phenomenon: effect of cold exposure. Arthritis Rheum 2002; 46: 1319-1323

30) Erre GL, De Muro P, Dellacà P, Fenu P, Cherchi GM, Faedda R et al. Iloprost therapy acutely decreases oxidative stress in patients affected by systemic sclerosis. Clin Exp Rheumatol 2008; 26:1095-1098

31) Hozo SP, Djulbegovic B, Hozo I. Estimating the Mean and Variance from the Median, Range, and the Size of a Sample. BMC Medical Research Methodology 2005; 5: 13 
32) Janssen LJ, Premji M, Netherton S, Coruzzi J, Lu-Chao H, Cox PG. Vasoconstrictor actions of isoprostanes via tyrosine kinase and Rho kinase in human and canine pulmonary vascular smooth muscles. $\mathrm{Br} \mathrm{J}$ Pharmacol 2001; 132: 127-134

33) Yura T, Fukunaga M, Khan R, Nassar GN, Badr KF, Montero A. Free-radical-generated F2-isoprostane stimulates cell proliferation and endothelin-1 expression on endothelial cells. Kidney Int 1999; 56: 471-478

34) Mostmans Y, Cutolo M, Giddelo C, Decuman S, Melsens K, Declercq H et al. The role of endothelial cells in the vasculopathy of systemic sclerosis: A systematic review. Autoimmun Rev 2017; 16:774-786

35) Tyndall AJ, Bannert B, Vonk M, et al. Causes and risk factors for death in systemic sclerosis: a study from the EULAR Scleroderma Trials and Research (EUSTAR) database. Ann Rheum Dis 2010; 69:1809-1815

36) Hansson P, Barregård L, Halltorp M, Sibthorpe S, Svelander C, Sandberg AS et al. Habitual high intake of fatty fish is related to lower levels of $\mathrm{F}_{2}$-isoprostane in healthy women. Nutrition 2015; 31: 847-852

37) Kitano S, Hisatomi H, Hibi N, Kawano K, Harada S. Improved method of plasma 8-Isoprostane measurement and association analyses with habitual drinking and smoking. World J Gastroenterol 2006; 12 : 5846-5852.

38) Morrow JD, Frei B, Longmire AW et al. Increase in circulating products of lipid peroxidation (F2isoprostanes) in smokers. Smoking as a cause of oxidative damage. N Engl J Med 1995; 332:1198-1203

39) Spadoni T, Svegliati Baroni S, Amico D, Albani L, Moroncini G, Avvedimento EV et al. A reactive oxygen species-mediated loop maintains increased expression of NADPH oxidases 2 and 4 in skin fibroblasts from patients with systemic sclerosis. Arthritis Rheumatol 2015; 67:1611-1622 


\section{Legend to figures}

Figure 1: Flow diagram of article selection. ${ }^{*} \mathrm{~N}=10$ records were excluded for the following reasons: $n=3$ dealt with in vitro studies, $n=2$ with oxidative damage to DNA, $n=2$ with antibodies against antioxidant enzymes, $n=1$ with heat shock proteins, $n=1$ with pentraxin, $n=1$ was a commentary on a previous article. $\bullet N=8$ full text excluded: $n=6$ dealing with oxidative stress but not containing data on isoprostane; $n=1$ isoprostane in breath; $\mathrm{n}=2$ review article.

Figure 2: forest plot of studies investigating urinary and serum isoprostane in systemic sclerosis compared to controls

Figure 3A: forest plot of studies investigating urinary isoprostane in systemic sclerosis compared to controls

Figure 3B: forest plot of studies investigating urinary isoprostane expressed in $\mathrm{pg} / \mathrm{mg}$ creatinine in systemic sclerosis compared to controls

Figure 3C: forest plot of studies investigating urinary isoprostane expressed in pmol/mmol creatinine in systemic sclerosis compared to controls

Figure 3D: forest plot of studies investigating serum isoprostane in systemic sclerosis compared to controls

Figure 4: forest plot of studies comparing urinary isoprostane in diffuse and limited systemic sclerosis 

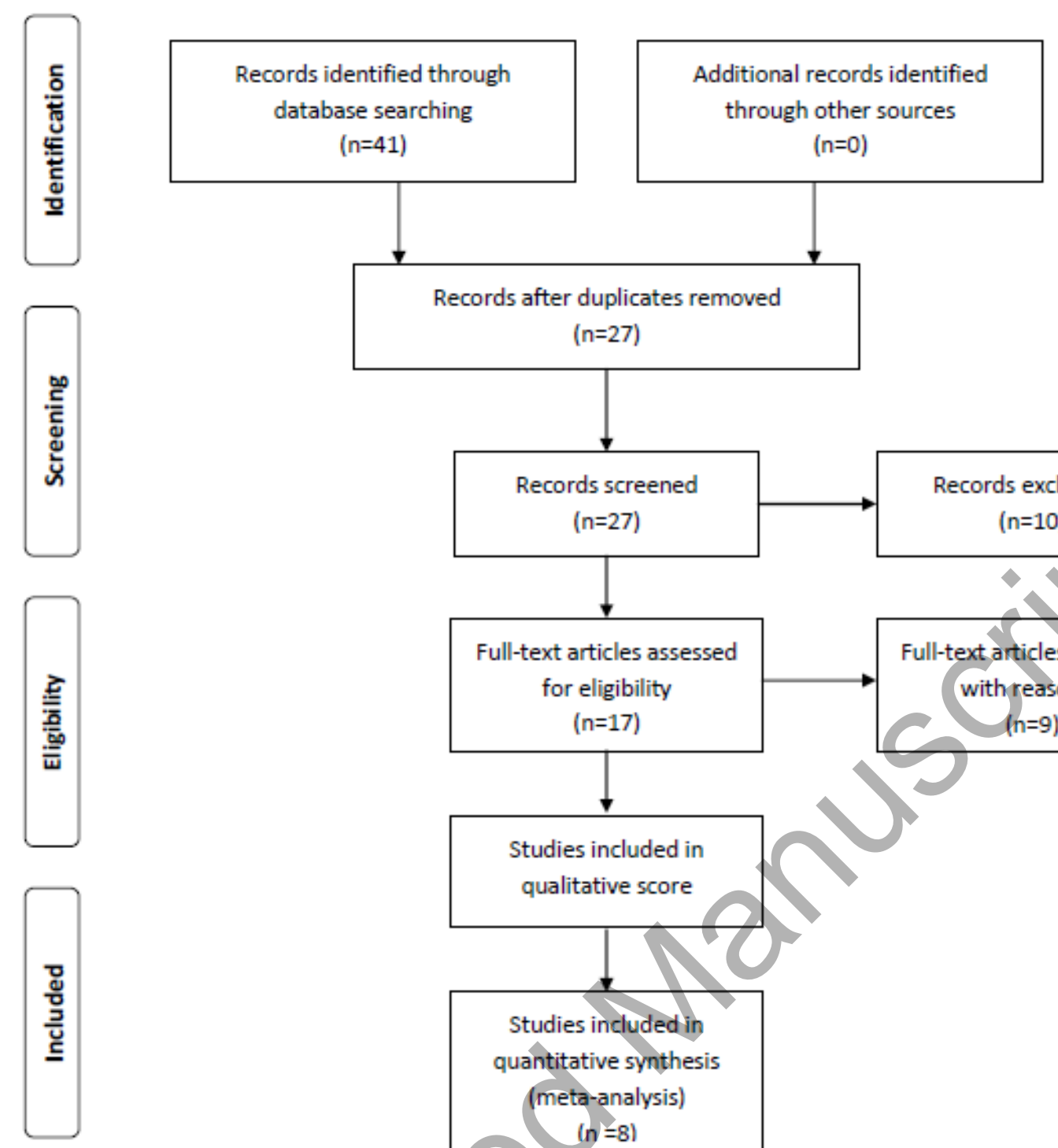

( $n=27$ )
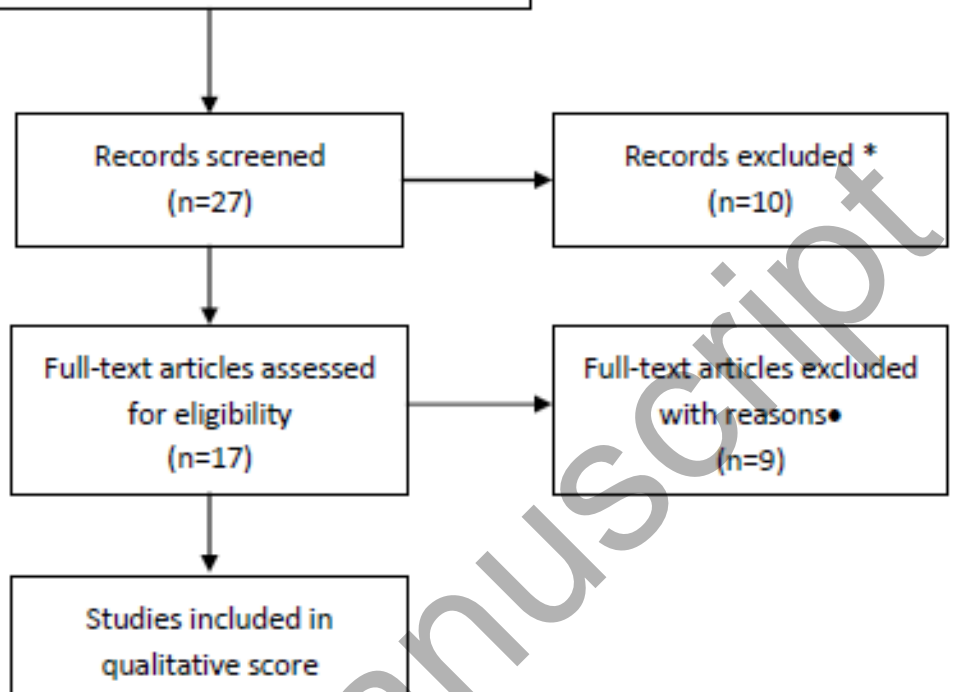

Figure 1

quantitative synthesis

(meta-analysis)

$(n=8)$ 
Isoprostane in systemic sclerosis

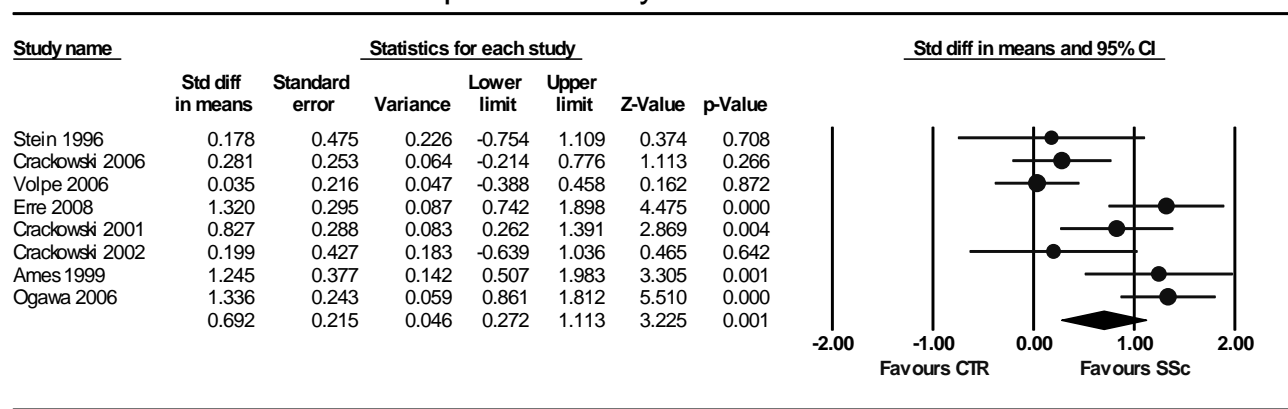

Overall: I squared $75 \%, p<0.0001$

Figure 2

Urinary isoprostane in systemic sclerosis

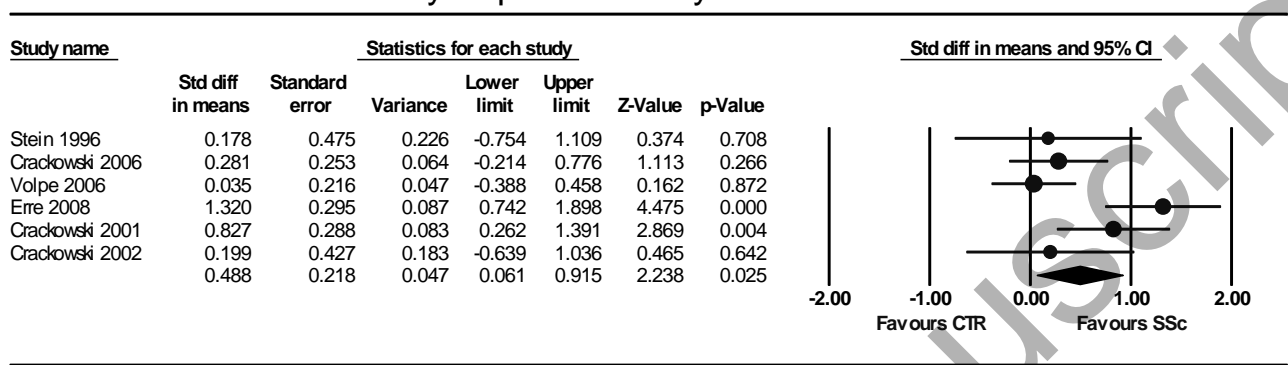

Overall: I squared 67\%, p=0.009

Figure 3A

Urinary isoprostane in systemic sclerosis

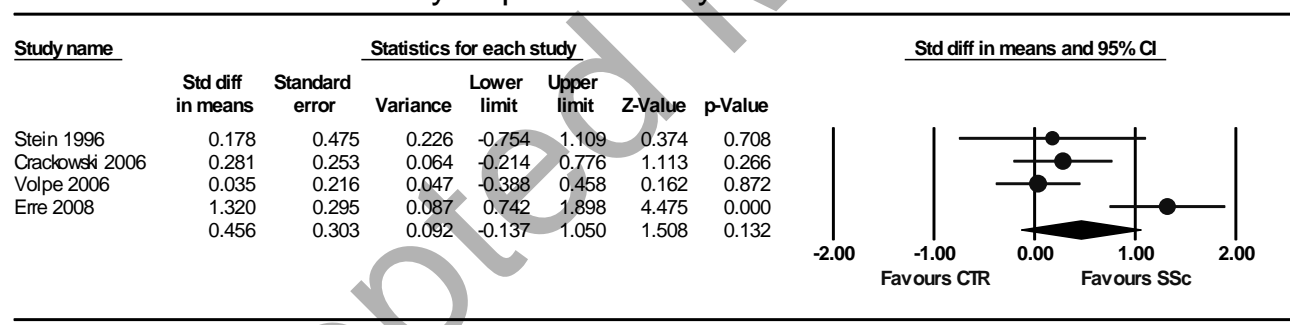

Overall: $\mid$ squared $76 \%, p=0.005$

Figure 3B

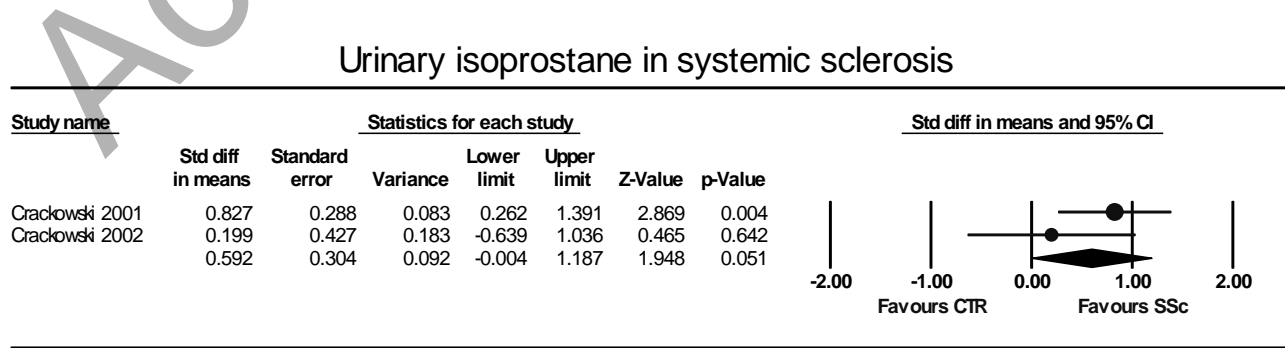

Overall: I squared $32 \%, p=0.2$

Figure $3 C$ 
Serum isoprostane in systemic sclerosis

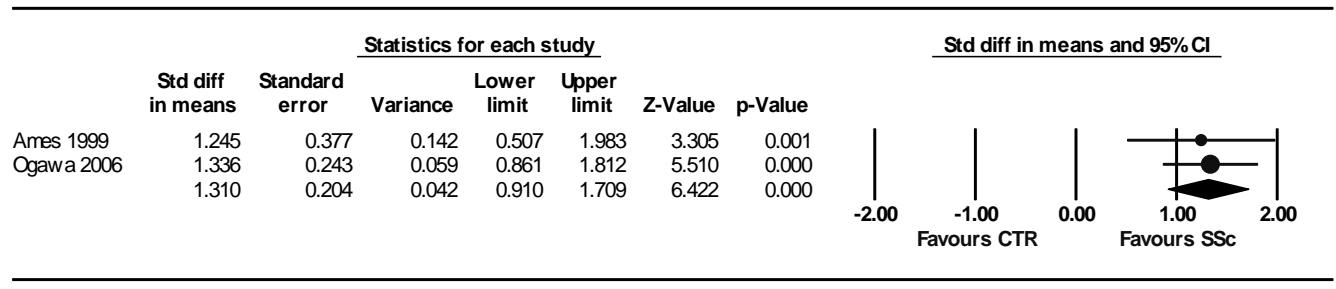

Overall: I squared $0 \%$

Figure 3D

Urinary isoprostane in diffuse and limited systemic sclerosis

\begin{tabular}{|c|c|c|c|c|c|c|c|c|}
\hline \multirow[t]{2}{*}{ Study name } & \multicolumn{7}{|c|}{ Statistics for each study } & \multirow[t]{2}{*}{ Std diff in means and $95 \% \mathrm{Cl}$} \\
\hline & $\begin{array}{l}\text { Std diff } \\
\text { in means }\end{array}$ & $\begin{array}{l}\text { Standard } \\
\text { error }\end{array}$ & Variance & $\begin{array}{c}\text { Lower } \\
\text { limit }\end{array}$ & $\begin{array}{c}\text { Upper } \\
\text { limit }\end{array}$ & Z-Value & p-Value & \\
\hline $\begin{array}{l}\text { Stein } 1996 \\
\text { Crackowsi } 2001 \\
\text { Erre } 2008\end{array}$ & $\begin{array}{l}0.026 \\
0.208 \\
0.250 \\
0.205\end{array}$ & $\begin{array}{l}0.730 \\
0.333 \\
0.380 \\
0.237\end{array}$ & $\begin{array}{l}0.533 \\
0.111 \\
0.145 \\
0.056\end{array}$ & $\begin{array}{l}-1.405 \\
-0.444 \\
-0.496 \\
-0.259\end{array}$ & $\begin{array}{l}1.458 \\
0.860 \\
0.995 \\
0.669\end{array}$ & $\begin{array}{l}0.036 \\
0.625 \\
0.657 \\
0.866\end{array}$ & $\begin{array}{l}0.971 \\
0.532 \\
0.511 \\
0.387\end{array}$ & \\
\hline
\end{tabular}

Figure 4 
Table 1A. Demographics and clinical manifestations of the studies included in meta-analysis

\begin{tabular}{|c|c|c|c|c|c|c|c|c|c|c|c|c|}
\hline & SSc & Age & $\mathbf{M} / \mathbf{F}$ & DD & dc/lc & $\mathbf{P F}$ & PAH & RD & CTR & Age & $\mathbf{M} / \mathbf{F}$ & NOW \\
\hline & No & Years & No & Years & No & $\%$ & $\%$ & $\%$ & No & Years & No & \\
\hline \multicolumn{13}{|l|}{ Urine studies } \\
\hline Stein 1996 & 8 & 51 & $1 / 7$ & 9.8 & $3 / 5$ & 25 & 12.5 & & 10 & 32.2 & $5 / 5$ & 5 \\
\hline $\begin{array}{l}\text { Crackowski } \\
2001\end{array}$ & 37 & 55 & $3 / 34$ & 17 & $21 / 16$ & 43 & & & 20 & 51 & $1 / 19$ & 6.5 \\
\hline $\begin{array}{l}\text { Crackowski } \\
2002\end{array}$ & 11 & 51 & 11 & 11 & $8 / 3$ & 36 & & & 11 & 50 & 11 & 5.5 \\
\hline $\begin{array}{l}\text { Crackowski } \\
2006\end{array}$ & 43 & 52 & $4 / 39$ & 5 & $9 / 34$ & 26 & 1 & 42 & 25 & 51 & 11 & 7 \\
\hline Volpe 2006 & 43 & $54 \pm 14$ & $1 / 42$ & 9 & $16 / 27$ & 51 & 16.3 & & 43 & $54 \pm 14$ & $1 / 42$ & 5 \\
\hline Erre 2008 & 28 & 54 & $22 / 6$ & 8.8 & $15 / 13$ & 33 & 28.6 & & 28 & 55 & $22 / 6$ & 5 \\
\hline \multicolumn{13}{|c|}{ Serum studies } \\
\hline Ames 1999 & 13 & $45 \pm 8$ & $3 / 10$ & 7.5 & $6 / 7$ & 30 & & & 23 & $40 \pm 13$ & $18 / 5$ & 6 \\
\hline Ogawa 2006 & 57 & $49 \pm 17$ & $9 / 48$ & 6.1 & $32 / 25$ & & & & 32 & $44 \pm 10$ & $4 / 28$ & 5.5 \\
\hline
\end{tabular}

Abbreviations. SSc: systemic sclerosis; M/F: male/female; DD: disease duration; dc: diffuse cutaneous; Ic limited cutaneous ; PF:pulmonary

fibrosis; PAH: pulmonary arterial hypertension; RD: renal disease; CTR: control; NOW: Newcastle-Ottawa scoring system; No: number.

Table 1B. Levels of isoprostanes of the studies included in meta-analysis

\begin{tabular}{|c|c|c|c|c|c|c|}
\hline & SSc & Isoprostane & CTR & Isoprostane & Calculated values & Units of measure \\
\hline & No & & No & & & \\
\hline \multicolumn{7}{|l|}{ Urine studies } \\
\hline Stein 1996 & 8 & $341 \pm 640$ & 10 & $112 \pm 140$ & mean \pm SEM & $\mathrm{pg} / \mathrm{mg}$ creatinine \\
\hline $\begin{array}{l}\text { Crackowski } \\
2001\end{array}$ & 37 & $232 \pm 28$ & 20 & $116 \pm 9$ & mean \pm SEM & $\begin{array}{c}\mathrm{pmol} / \mathrm{mmol} \\
\text { creatinine }\end{array}$ \\
\hline $\begin{array}{l}\text { Crackowski } \\
2002\end{array}$ & 11 & $178 \pm 32$ & 11 & $95 \pm 11$ & mean \pm SEM & $\begin{array}{l}\mathrm{pmol} / \mathrm{mmol} \\
\text { creatinine }\end{array}$ \\
\hline $\begin{array}{l}\text { Crackowski } \\
2006\end{array}$ & 43 & $230(155,387)$ & 25 & $207(109,291)$ & $\begin{array}{c}\text { median }\left(10^{\text {th }}-90^{\text {th }}\right. \\
\text { PCL })\end{array}$ & $\mathrm{pg} / \mathrm{mg}$ creatinine \\
\hline Volpe 2006 & 43 & $342(341,343)$ & 43 & $148(146,149)$ & mean $(95 \% \mathrm{CI})$ & pg/mg creatinine \\
\hline Erre 2008 & 28 & $\begin{array}{c}2002(1122- \\
3575)\end{array}$ & 28 & $334(226-441)$ & median (IQR) & $\mathrm{pg} / \mathrm{mg}$ creatinine \\
\hline \multicolumn{7}{|c|}{ Serum studies } \\
\hline Ames 1999 & 13 & $196 \pm 160$ & 23 & $69 \pm 46$ & mean \pm SD & $\mathrm{pg} / \mathrm{ml}$ \\
\hline Ogawa 2006 & 57 & $\begin{array}{l}441(13- \\
154879)\end{array}$ & 32 & $6(2-34)$ & median (range) & $\mathrm{pg} / \mathrm{ml}$ \\
\hline
\end{tabular}

Abbreviations. SSc: systemic sclerosis; CTR: control; No: number; SEM: standard error of mean; PCL: percentile; IQR:

interquartile range; SD: standard deviation. 